\title{
ARBORIZAÇÃO DA AVENIDA ADOLF JOHN TERRY E OS CONFLITOS COM EQUIPAMENTOS URBANOS, CORRENTE-PI
}

Arborization of Adolf John Terry Avenue and conflicts with urban facilities, Currente-PI

\author{
Laurenice s. da costa ${ }^{1}$ \\ Thailana L. Marques ${ }^{1}$ \\ Gilvaneide A. de Aguiar ${ }^{1}$ \\ José B. da Costa ${ }^{1}$ \\ Ricardo V. Balduino ${ }^{1}$ \\ Bruna de F. Iwata ${ }^{1}$
}

RESUMO: A introdução de árvores em vias públicas sem conhecer as particularidades de cada espécie geram conflitos com equipamentos urbanos como fiações elétricas, encanamentos, calhas, calçamentos, muros, e postes de iluminação. O poder público é o fundamental responsável por políticas de preservação, recuperação e ampliação dos exemplares arbóreos, dando relevância ao cumprimento dos planos de arborização e devendo também propor novas atualizações dessas normativas. Este trabalho tem por objetivo realizar um levantamento qualitativo, identificando as particularidades de todas as espécies, e a quantificação dos conflitos gerados pela arborização na Avenida Adolf John Terry, localizada no município de Corrente - PI. Para isto, foi feito um levantamento dos indivíduos arbóreos existentes nos canteiros centrais da avenida, assim como a identificação das espécies, realizada por meio do conhecimento popular local, para identificação da denominação popular de cada indivíduo. Dos 78 indivíduos encontrados, prevaleceu as espécies exóticas, no qual observou-se que a maior parte desses indivíduos arbóreos geram conflitos com o meio devido à falta de planejamento e escolha inadequada das espécies. Levando então a geração de vários conflitos com os equipamentos urbanos, como o porte é inadequado das arvores, interferindo na fiação elétrica da avenida.

PALAVRAS-CHAVE: Arborização Urbana, Planejamento Urbano e Equipamentos Urbanos.

\begin{abstract}
The introduction of trees on public roads without knowing the particularities of each species generate conflicts with urban equipment such as electrical wiring, plumbing, gutters, sidewalks, walls and lampposts. The government is the key responsible for preservation policies, recovery and expansion of arboreal specimens, giving importance to the fulfillment of afforestation plans and should also propose new updates of these regulations. This study aims to conduct a qualitative survey, identifying the characteristics of each species and quantify the
\end{abstract}

\footnotetext{
${ }^{1}$ Instituto Federal de Educação, Ciência e tecnologia do Piauí - IFPI.
} 
conflicts generated. by afforestation on Avenue Adolf John Terry, located in the current municipality - PI. For this, a survey was made of existing individual trees in medians Avenue, as well as the identification of species, held by the local popular knowledge for identification of the popular each individual denomination. It was observed that the choice of species and afforestation plan is essential to avoid many losses that can lead to society.

\section{KEYWORDS: Urban Afforestation, Urban Planning e Urban Equipment.}

\section{INTRODUÇÃO}

A predominância de vegetação arbórea e de solo livre de edificações nos centros urbanos enfatiza as funções ecológicas (aumento do conforto térmico, controle da poluição do ar e acústica, interceptação das águas das chuvas, e abrigo à fauna), estéticas (valorização visual e ornamental do ambiente e diversificação da paisagem construída) e de lazer (recreação) que estas áreas podem exercer (BARGOS e MATIAS, 2012).

O poder público é o principal responsável por políticas de preservação, recuperação e ampliação dos exemplares arbóreos, dando relevância ao cumprimento dos planos de arborização e devendo também propor novas atualizações dessas normativas. As espécies adequadas e o planejamento da arborização urbana é fundamental, frente aos inúmeros prejuízos que podem acarretar para a sociedade e para os equipamentos urbanos Cechetto et al (2014).

A sociedade que se beneficia das funções da arborização reconhece a sua importância visto que a vegetação urbana é um fator de amenidades climáticas e causadoras de sensação de bem-estar térmico. Cumprindo funções fundamentais na dinâmica natural do meio ambiente, na recarga hídrica de reservatórios, lenções freáticos e cursos d'água, na proteção e fertilização do solo, no modelado do relevo, na manutenção e proteção da fauna, na purificação do ar, etc. Barbosa e Dorigon (2014).

A introdução de árvores em vias públicas sem conhecer as particularidades de cada espécie geram conflitos com equipamentos urbanos como fiações elétricas, encanamentos, calhas, calçamentos, muros, e postes de iluminação. Estes problemas são muito comuns de serem visualizados e causa, na maioria das vezes, um manejo inadequado e prejudicial às árvores Ribeiro (2009).

Conforme Coletto et al (2008) a maior parte dos problemas verificados decorre dos plantios voluntários promovidos pelos próprios moradores, nos quais não há observância aos padrões técnicos, o que ocasiona vários conflitos nos centros urbanos. Diante disso, este trabalho tem por objetivo realizar um levantamento qualitativo, identificando as particularidade de todas 
as espécies e quantificar os conflitos gerados pela arborização na Avenida Adolf John Terry, localizada no município de Corrente - PI.

\section{MATERIAL E MÉTODOS}

\section{Área de estudo}

O estudo foi realizado na cidade de Corrente, localizada na Mesorregião das Chapadas do Extremo Sul Piauiense, com área de $3.051 .161 \mathrm{~km}^{2}$. A sede do município está entre as coordenadas geográficas $\left(10^{\circ} 26^{\prime} 34^{\prime}\right.$ de latitude sul e $45^{\circ}$ 09' 43' de longitude oeste de Greenwich) segundo IBGE (2010) e distancia-se 874 km da capital do Estado do Piaú́, Teresina. A área de estudo está localizada no bairro centro, perímetro urbano do município de Corrente PI, é uma importante Avenida caracterizada como comercial com comprimento total de $1,84 \mathrm{~km}$. (figura 1).

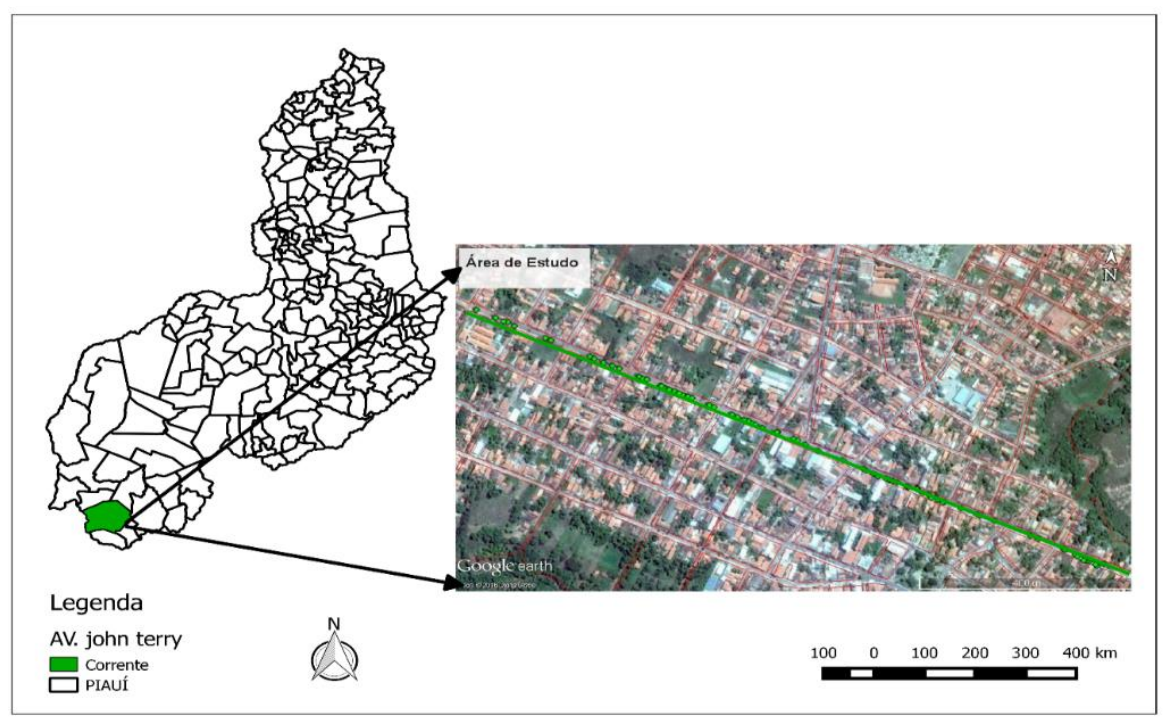

Figura 1. Vista área da localização da Avenida Adolf John Terry.

Fonte: Laurenice Severina da Costa, 2016.

O clima do munícipio de Corrente-PI, conforme o IBGE (2002) é semiúmido com o período de cinco messes de estação seca. Apresenta as temperaturas de $32^{\circ} \mathrm{C}$ e precipitação pluviométrica média anual (na sede) entre 1000 e 1200 mm (ANDRADE JÚNIOR, 2014), definida pelo Regime Equatorial Continental (IBGE, 1997 apud Aguiar, 2004). A cidade de Corrente tem uma população estimada em aproximadamente 25.408 habitantes somando a área rural e urbana. Possui 15 bairros sendo que a região central do munícipio caracterizado como de usos: residencial e comercial.

\section{Procedimentos Metodológicos}


O diagnóstico foi efetuado com o uso de uma planilha de levantamento de dados, coletando-se dados referentes à avenida e aos indivíduos vegetais existentes no canteiro com o uso de um GPS para marcar os postos da localização dos indivíduos arbóreos. A metodologia empregada consistiu no levantamento de todos os indivíduos arbóreos existentes nos canteiros centrais da avenida, assim como a identificação das espécies, realizada por meio do conhecimento popular local, para identificação da denominação popular de cada indivíduo e posteriores denominações científicas das espécies.

Em relação a avenida, foram levantados os seguintes dados: área total (largura e comprimento) da avenida, largura do canteiro, conflito com os equipamentos urbanos: iluminação, fiação, canteiro e veículos. Em relação aos indivíduos vegetais, foram levantados: espécie (nome vulgar e cientifico), circunferência à altura do peito (CAP), espaçamento entre os indivíduos, altura total, altura do fuste, altura da copa, diâmetro à altura do peito (DAP), altura da primeira bifurcação, sombra, comportamento do fuste, saúde do indivíduos. As variáveis estudadas foram selecionadas conforme embasamento literário de outros estudos (COLETO et al (2008), FARIA et al (2007) e ROCHA et al(2004)).

\section{RESULTADOS E DISCUSSÃO}

O estudo verificou que a arborização da Avenida Adolfo John Terry foi implementada sem conhecimentos técnicos necessários na época (1980) da sua inserção, com um total de 78 indivíduos, observa-se que depois de passados 30 anos surge os inúmeros conflitos com os equipamentos urbanos e passagem de veículo que são vivenciados diariamente pela população urbana.

Os 78 indivíduos arbóreos quantificados pertencem à 9 espécies distintas (Tabela 1), sendo que dentre elas se destaca uma espécies não identificada com o nome vulgar coronha (33,33\%) em seguida se destaca Moquilea tomentosa (25,64\%), Azadirachta (11,53\%) e Terminalia catappa $(11,53 \%)$ espécies que respondem mais de 60\% da arborização do município, por terem grandes copas geram ótimas sombras para a população mais são indivíduos que em locais inadequados geram inúmeros conflitos.

Tabela 1. Diversidade florística da arborização da avenida Adolf John Terry

\begin{tabular}{llccc}
\hline Nome científico & Nome vulgar & Origem & Número de Indivíduos & Frequência (\%) \\
\hline Aqadirachta indica & Ninho & $\mathrm{E}$ & 9 & $11,53 \%$ \\
Moquilea tomentosa & Oiti & $\mathrm{N}$ & 20 & $25,64 \%$ \\
Mangifera Indica & Mangueira & $\mathrm{E}$ & 7 & $8,97 \%$ \\
Pacbira aquática & Manguba & $\mathrm{N}$ & 2 & $2,56 \%$
\end{tabular}




$\begin{array}{llccl}\text { Terminalia catappa } & \text { Amêndoa } & \text { E } & 9 & 11,53 \% \\ \text { Não identificada } & \text { Coronha } & - & 26 & 33,33 \% \\ \text { Não identificada } & \text { São João } & - & 2 & 2,56 \% \\ \text { Ficus benjamina } & \text { Fícus } & \text { E } & 1 & 1,28 \\ \text { Anacardium occidentale } & \text { Cajueiro } & \text { N } & 1 & 1,28 \%\end{array}$

Nativa (N); Exótica (E)

$\mathrm{Na}$ análise dos conflitos existentes na arborização da área em estudo predominou o confronto entre os indivíduos arbóreos com: os veículos, as fiação elétrica, canteiro central e poste de iluminação (Tabela 2). Os indivíduos também sofrem impactos ambientais de todas as formas, ou seja, galhos quebrados, podas em excesso, tudo devido à falta de planejamento e a escolha de espécies inadequadas Cecchetto et al (2014).

O conflito que apresentou maiores porcentuais foi com a fiação elétrica sendo que as espécies que levaram esse conflito foram Mangifera Indica e Pachira aquática, já os conflitos com menor porcentagem foi poste de iluminação destacando as espécies oiti e mangueira, as espécies que apresentou maiores porcentuais de conflitos foram: Moquilea tomentosa, Aqadirachta indica e coronha. Alguns indivíduos na área em estudo não geram conflitos com os equipamentos urbanos, mas são espécies ainda jovens como: Ficus benjamina e Anacardium occidentale (Tabela 2).

Tabela 2. Conflitos das espécies arbóreas e os equipamentos urbanos

\begin{tabular}{lcccc}
\hline Individuo & Canteiro & Fiação elétrica & Poste de Iluminação & Veículos \\
\hline Oiti & $30,4 \%$ & $30,4 \%$ & $26 \%$ & $13,2 \%$ \\
Mangueira & $25 \%$ & $50 \%$ & $25 \%$ & $0 \%$ \\
Amêndoa & $23 \%$ & $46,1 \%$ & $7,9 \%$ & $23 \%$ \\
Coronha & $20 \%$ & 21,8 & $12,8 \%$ & $45,4 \%$ \\
Manguba & $50 \%$ & $50 \%$ & $0 \%$ & $0 \%$ \\
Ninho & $13,3 \%$ & $33,3 \%$ & $13,4 \%$ & $40 \%$ \\
São João & $0 \%$ & $0 \%$ & $0 \%$ & $100 \%$ \\
Fícus & $0 \%$ & $0 \%$ & $0 \%$ & $0 \%$ \\
Cajueiro & $0 \%$ & $0 \%$ & $0 \%$ & $0 \%$ \\
\hline
\end{tabular}

Em relação à condição geral da saúde dos indivíduos arbóreos foram avaliados e classificados em quatro categorias. 28 indivíduos (35\%), foram classificados como árvore sem sinal de alteração, As arvores classificadas como danificadas foram 21 indivíduos (26\%), as arvores classificadas como degenerandos foram 5 indivíduos $(9 \%)$, em pequenos números foram as classificadas como sadias 5 indivíduos ( $6 \%$ ) um número insignificativo se comparamos com a demais classificações que se encontrava com o fuste e a copa danificadas pela população como também pelos equipamentos urbanos. 
Do total de 37 indivíduos identificados foram avaliados como geradores de conflitos com veículos, gerando transtornos para a população, por ser uma importante avenida comercial; para obtermos esses dados esperavam-se veículos de grandes portes passarem próximos aos indivíduos, muitas das vezes os veículos danificavam as copas das arvores. Outros 20 indivíduos são geradores de conflitos com o canteiro central pelo afloramento das raízes (Figura 2).
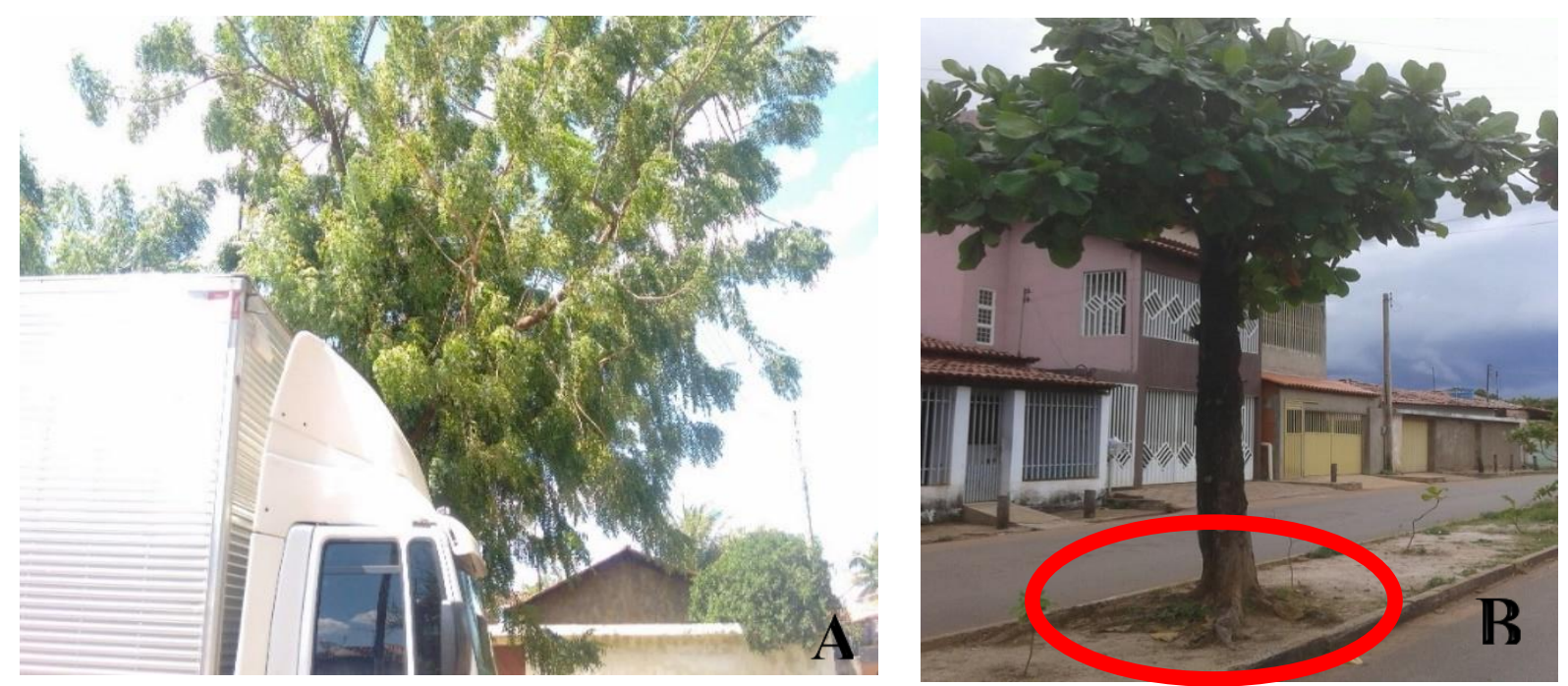

Figura 2. A) Conflito da arborização com veículos, B) Conflito da arborização com o canteiro central. Fonte: Levantamento de campo, 2016.

Foram identificados 33 indivíduos em conflitos com a fiação elétrica, são redes convencionais e sem proteção, ao qual a solução utilizada pela companhia de energia que atende todo o município são as podas, mais em pouco tempo os indivíduos estavam novamente em contato com a fiação, tendo que realizar podas anualmente por serem redes muito baixa e arvores de grandes portes. Os indivíduos que foram identificados com geradores de conflitos com os postes de iluminação chegou um total de 17 indivíduos (Figura 3). 

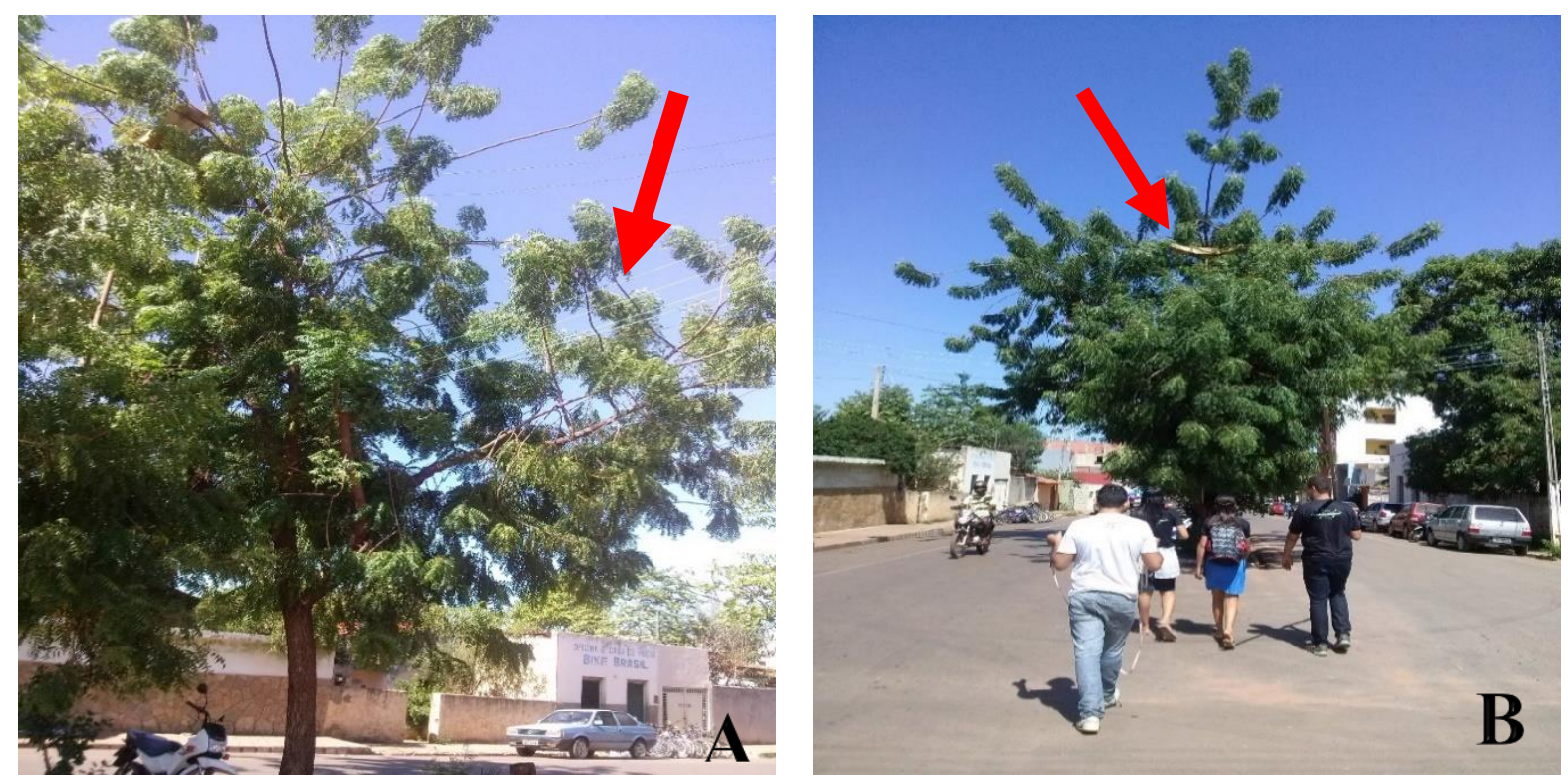

Figura 3. A) conflito da arborização com fiação elétrica, B) conflito da arborização com porte de iluminação.Fonte: Levantamento,2016.

Os espaçamentos existentes entre as árvores foram avaliados, tendo sido verificado espaçamentos mínimo de 1 metro, médio de 3 metros e o máximo de 13 metros. Foi possível perceber que a população tem plantado mudas e não obedece aos espaçamentos mínimos recomendados, o que posteriormente quando adultos poderão gerar conflitos em função de sua dimensão (diâmetro de copa) quando adulta além de serem espécies que quando adulta apresentam características inadequadas para avenida.

O comportamento do fuste foi um parâmetro analisado nos 87 indivíduos, o comportamento que predominou foi 0,9 em seguida 0,7 e o que teve menor frequência foi 0,3, todos os indivíduos que apresentou comportamento do fuste 0,3 foram encontrados alguns tipos de conflitos principalmente com veículos e fiação elétrica.

Fuste comportamento

0,9

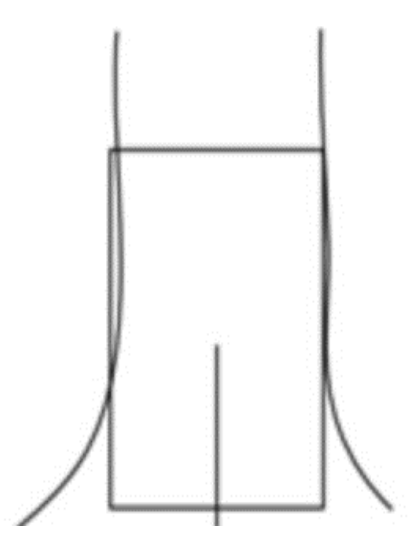

Fuste comportamento

0,7

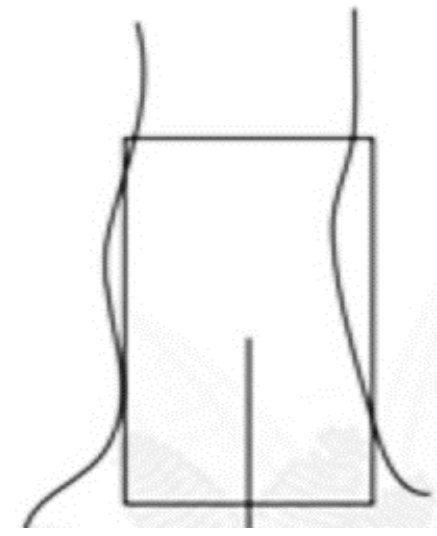

Fuste comportamento

0,3 

Q. Total: 36
Q. Total: 31
Q. Total: 11

Figura 4. Comportamento do fuste dos indivíduos da Avenida Adolf John Terry.

Fonte: Bruna de Freitas Iwata, 2016.

A distribuição média da altura dos indivíduos estudados apresentaram variações dependendo da espécie, representando com as maiores médias o Azadirachta indica, Moquilea tomentosa e coronha como mostra a Figura 4. A) tendo relação com a análise dos conflitos por terem sido espécies que apresentou um porcentual muito elevado de conflitos.

A altura média do fuste como mostra a Figura 4. B) dentre as espécies que apresentou maiores médias foram coronha, amêndoa e oiti enquanto as espécies que teve maiores médias da altura da copa foram Azadirachta indica, Moquilea tomentosa e manguba sendo espécies que na tabela de conflitos apresentam porcentuais elevados com fiação elétrica (Figura C).

A circunferência a altura do peito (CAP) e o diâmetro a altura do peito (DAP) foram parâmetros que também foram identificados nos indivíduos arbóreos da arborização na avenida em estudo, as espécies com médias significativas foram Moquilea tomentosa, Mangifera Indica e coronha, com a menor média de CAP de 0,24m (Ficus benjamina) e os maiores de 1,36m (Moquilea tomentosa) no DAP a menor média foi e $0,07 \mathrm{~m}$ (Ficus benjamina) e a maior média foi de $0,45 \mathrm{~m}$ (Moquilea tomentosa) como mostra a figura 4. E e F ao comparar esses valores com o trabalho Coletto et al (2008) onde o CAP mínimo encontrado foi de apenas $2 \mathrm{~cm}$, o máximo foi de 2,63 cm e a média avaliada foi de $58,7 \mathrm{~cm}$ (diâmetro à altura do peito - DAP - de aproximadamente $19 \mathrm{~cm}$ ) os valores foram distintos.

A média da altura da primeira bifurcação como mostra a Figura 4. D) as espécies que tiveram maiores médias foram: Terminalia catappa $(3,31 \mathrm{~m})$, Ficus benjamina $(2,25 \mathrm{~m})$ e coronha $(2,08 \mathrm{~m})$ já a espécie que apresentou a menor média foi Mangifera Indica $(0,82 \mathrm{~m})$. 

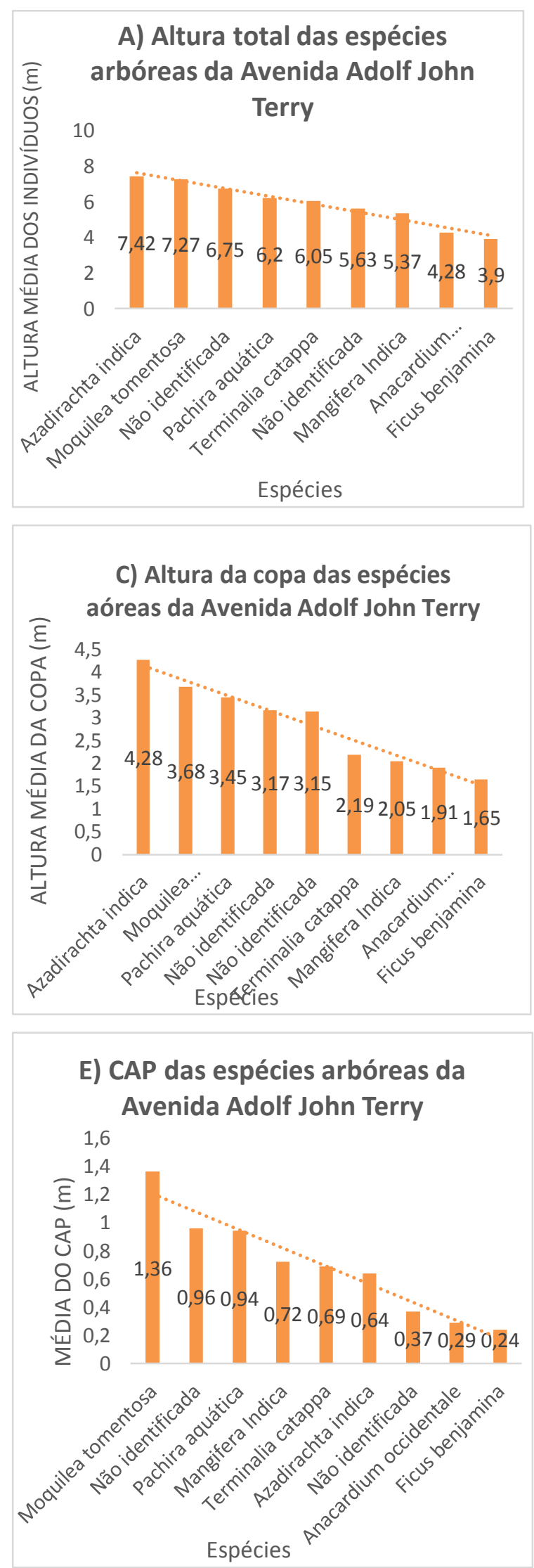
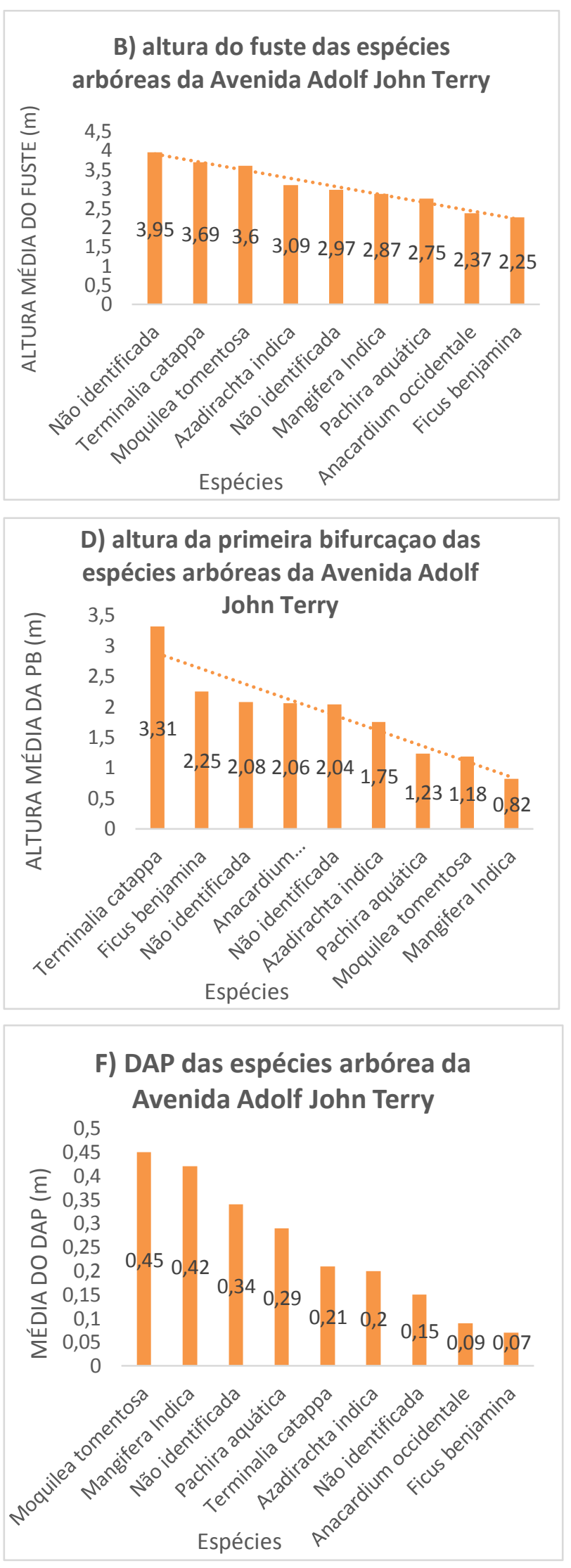

Figura 5. Levantamento quali - quantitativo da arborização na Avenida Adolf John Terry.

Fonte: Levantamento, 2016. 
A área sombreada pelos indivíduos arbóreos na Avenida Adolf John Terry representa para a população dentre vários benefícios o bem-estar não só na área em estudo mas também para toda a sociedade em geral.

Em árvores com copas abundantes consequentemente as sombras serão maiores, porém na área de estudo foram identificados poucos indivíduos que possuem essa qualidade, como mostra a tabela 4. Pois a área de sombra é inferior se comparado com o comprimento e largura da avenida. Constatando que existem poucos indivíduos arbóreos plantados e os pouco que se encontra foram plantados de forma inadequada, gerando algum tipo de conflito com os equipamentos urbanos

\begin{tabular}{cccc}
\hline Comprimento da Avenida & Largura da Avenida & Largura do Canteiro & Área de Sobra \\
\hline $1,84 \mathrm{~km}$ & $12,25 \mathrm{~m}$ & $2 \mathrm{~m}$ & $98,71 \mathrm{~m}$ \\
\hline
\end{tabular}

Tabela 4. Sombreamento da arborização na Avenida Adolf John Terry

\section{CONSIDERAÇÕES FINAIS}

A arborização na Avenida Adolf John Terry é composta por 78 indivíduos, prevalecendo as espécies exóticas, no qual observou-se que a maior parte desses indivíduos arbóreos geram conflitos com o meio devido à falta de planejamento e escolha inadequada das espécies. Levando então a geração de vários conflitos com os equipamentos urbanos, com o porte inadequado das arvores interferindo na fiação elétrica da avenida.

A escolha das espécies e o plano de arborização são fundamentais para evitar inúmeros prejuízos que podem acarretar para a sociedade, visto que o papel da arborização e trazer benefícios para a sociedade e não conflitos.

\section{REFERÊNCIAS}

ANDRADE JUNIOR, A. S. et al. "Atlas Climatológicas do Estado do Piauí. Teresina". In: Embrapa Meio- Norte, 2004.

BARBOSA, Liriane Gonçalves ${ }^{1}$; DORIGON, Larissa Piffer $^{2}$. Análise temporal da cobertura vegetal no município de Teresina/PI a partir da aplicação de NDVI. In: Programa de PósGraduação em Geografia, 2014

BARGOS, Danubia Caporusso ${ }^{1}$; MATIAS, Lindon Fonseca ${ }^{2}$. Mapeamento e análise de áreas verdes urbanas em Paulínia (SP): estudo com a aplicação de geotecnologias. In: Soc. \& Nat., Uberlândia, ano 24 n. 1, 143-156, jan/abr, 2012. 
CECCHETTO, Carise Taciane ${ }^{1}$; CHRISTMANN, Samara Simon²; OLIVEIRA, Tarcísio Dorn $\mathrm{de}^{3}$. Arborização urbana: importância e benefícios no planejamento ambiental das cidades. In: XVI Seminário Internacional de Educação no Mercosul, 2014

COLETTO, Elizete Patrícia ${ }^{1}$; MÜLLER, Nilvane G. ${ }^{2}$; WOLSKI, Silvia Scherer ${ }^{3}$. Diagnóstico da arborização das vias públicas do município de Sete de Setembro - RS. In: Rev. SBAU, Piracicaba, v.3, n.2, jun. 2008, p.110-122,2008.

INSTITUTO BRASILEIRO DE GEOGRAFIA E ESTATISTICAS- IBGE. Sinopse do Censo Demográfica 2010: Municípios do Piauí. www.ibge.gov.br. (Último acesso em 18/02/2016).

MAYER, Cleverson Luiz Dias. Análise de conflitos da arborização de vias públicas utilizando sistemas de informações geográficas: caso Irati, Paraná. In: Dissertação de mestrado, Irati-PR, 2012.

RIBEIRO, Flávia Alice Borges Soares. Arborização urbana em Uberlândia: percepção da população. In: Revista da Católica, v. 1, n. 1, p. 224-237, Uberlândia, 2009. 